\title{
Development of a Powder-feed Device and Procedures for the Application of an Experimental Alloy in Overhead PTA-P Welding
}

\author{
Jônathas Alexandre Alves ${ }^{1 *}$, Régis Henrique Gonçalves e Silva ${ }^{1}$, Jair Carlos Dutra ${ }^{1}$ \\ ${ }^{1}$ Department of Mechanical Engineering, Universidade Federal de Santa Catarina - UFSC, Florianópolis, SC, Brazil.
}

Received: 06 Nov., 2015

Accepted: 06 Nov., 2015

E-mail: jonathas.alves@posgrad.ufsc.br (JAA)

\begin{abstract}
When they are damaged by cavitation, hydroelectric power plant turbine blades must be repaired using operations that could benefit from developments in welding technologies. In light of this, the LABSOLDA welding laboratory at the Federal University of Santa Catarina is making efforts to enhance the flexibility and robustness of the powder-fed plasma transferred arc (PTA-P) process so that it can be used in any welding position and with different powders. The use of consumables in powder form in PTA-P welding allows experiments to be carried out to develop an alloy with special properties suitable for use in generator repairs. To this end, the RV-F PF powder feeder, which can operate with consumables with non-standard morphologies and particle sizes, was developed. The feeder was required to provide a regular flow of consumable material in out-of-position welding operations without the need for high gas flow rates and regardless of the morphology or particle size of the consumables. The RV-F $\mathrm{PF}$ is shown to operate efficiently with materials whose properties differ greatly from those of standard consumables. It is also suitable for overhead PTA-P welding and provides a constant supply of filler material efficiently with normal gas flow rates. The welding tests carried out involved deposition of a mixture of two alloys and were followed by cavitation testing of the resulting coating.
\end{abstract}

Key-words: Hydraulic turbines; Cavitation; PTA-P; Powder feeder; Experimental mixture.

\section{Introduction}

Because of its immense water reserves, Brazil has become highly dependent on hydroelectric power plants to meet its electricity needs [1]. A common problem in many power plants that affects turbine blades is cavitation. This is an erosive wear phenomenon that changes the shape of the blades, reducing generator performance. The blades are reconstructed using welding to replace the eroded material. Currently, thermal pulsed MIG/MAG welding, which was developed by LABSOLDA, is used with satisfactory results in some Brazilian power plants [2]. However, as part of LABSOLDA's commitment to supply the electricity generating sector with Brazilian technology, this paper proposes the use of powder-fed plasma transferred arc (PTA-P) in the repair of hydraulic turbines.

The way in which materials are processed in PTA-P means that this welding process can produce low dilution levels and a very regular surface finish [3,4], allowing both the number of passes required to produce the desired chemical composition on the surface of turbine blades and the amount of material that must be removed by grinding to be reduced. Furthermore, when powder filler is used, experimental alloys can be developed with different metal powder mixtures [5]. In this way, PTA-P can be used to develop alloys with high cavitation resistance and also to apply these alloys in turbine repairs. However, this requires a powder feeder (PF) to send the powder to the welding torch, which places it in the arc, where it melts and is transferred to the melt pool.

When experimental alloys are being developed, the PF often has to work with non-standard powders made up of particles with different shapes and sizes from those normally used in PTA-P [6]. Morphology and particle size have a strong influence on the flow properties of powders, which in turn affect the operation of normal feeders as these are designed to handle metal alloy powders already in industrial use and with particle sizes and shapes suitable for the PTA-P process [7]. To allow PTA-P to be used in the repair of hydraulic turbines (overhead welding), a PF must be able to send the consumable in the opposite direction to gravity. Although the pneumatic conveying mechanism used in PFs to send the powder to the melt pool allows the speed of the particles to be increased
This is an Open Access article distributed under the terms of the Creative Commons Attribution Non-Commercial License which permits unrestricted non-commercial use, distribution, and reproduction in any medium provided the original work is properly cited. 
Development of a Powder-Feed Device and Procedures for the Application of an Experimental Alloy in Overhead PTA-P Welding

by increasing the transport gas flow rate, gas flow rates higher than those normally used can cause undesirable interference in the electric arc and track geometry, make it difficult for the powder to melt and lead to inadequate penetration at the edges of the tracks [8].

In light of these difficulties, the present authors sought to develop a new type of PF for use in PTA-P. The PF was required to feed the powder in such a way as to allow out-of-position PTA-P welding using materials with non-standard particle sizes and shapes. Validation testing consisted of tests to assess whether the PF could handle some materials used to develop alloys and deposition of a mixture of two alloys in the overhead position. The PF was required to be suitable for use with PTA-P to produce a coating of sufficient quality to yield a defect-free test specimen for use in a cavitation test.

\section{Some Considerations about Powder Feeding in the Pta-P Process}

Figure 1 shows a schematic diagram of a basic feeding arrangement for consumable material in a PTA-P welding process.

As shown in Figure 1, a PF (which is generally installed above the torch) consists of a consumable dosing mechanism and a hopper to store the consumable. After dosing, the material is conveyed from the PF to the welding torch through a pneumatic feed. This consists of a hose through which the powder particles diffused in a stream of gas known as carrier gas flow. The torch in turn has internal channels that route the powder to the electric arc, where the particles melt to form the track.

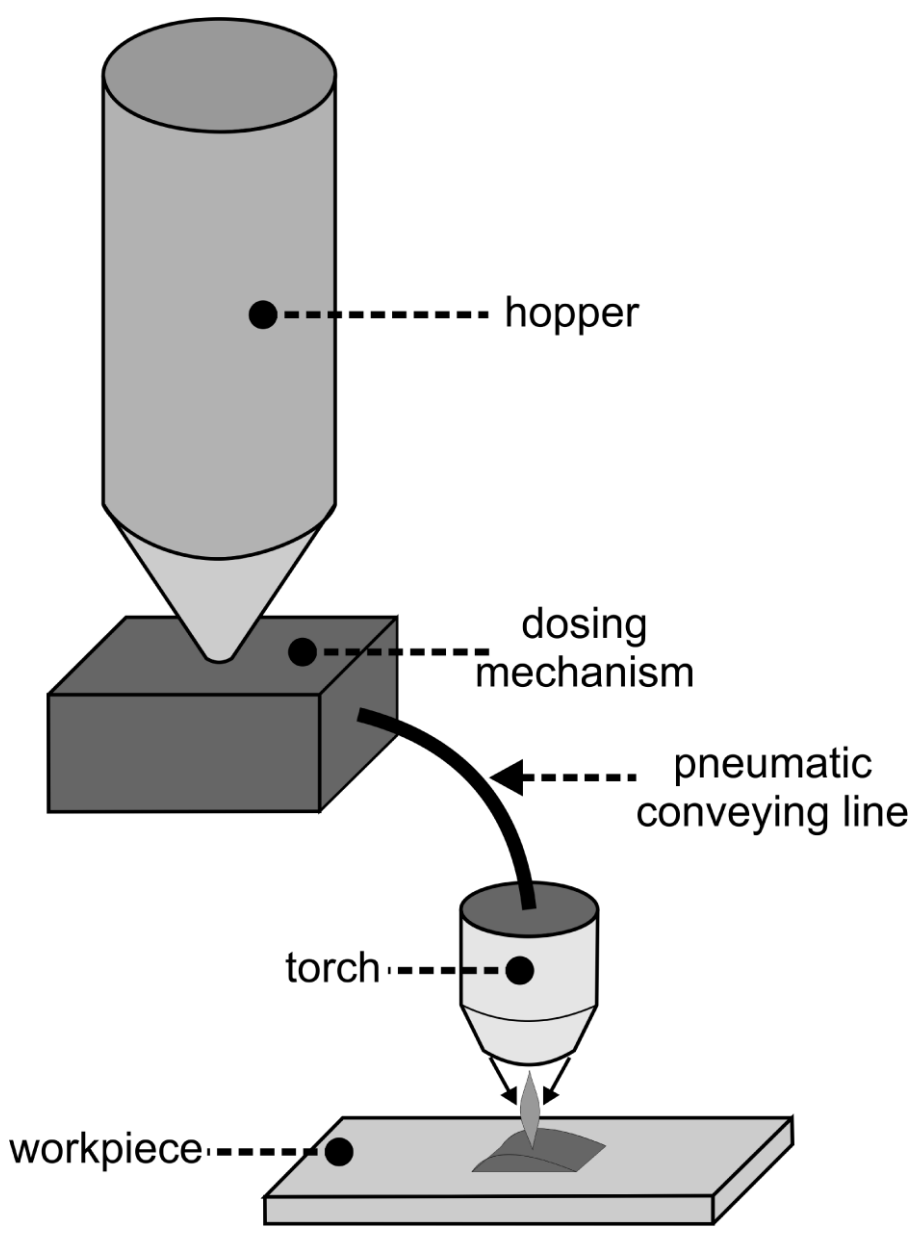

Figure 1. Simplified schematic diagram of the powder feed arrangement for PTA-P welding. 
The powders normally used in PTA-P are made up of spherical particles (produced by atomization) with standard diameters between 50 and $250 \mu \mathrm{m}$ for ferrous alloys. Figure 2a shows the particle size, morphology and flow characteristics of a powder produced for use with PTA-P. These properties are used to characterize the melting of the consumable during the PTA-P process and to ensure that the material flows satisfactorily inside the feeders. Figure $2 b$ shows a powder with a smaller particle size, while in Figure $2 c$ the powder is made up of smaller, irregular-shaped particles (produced by milling). As can be seen from the behavior of these powders during funnel flow (upper-left corner of each figure), these characteristics lead to flow defects that adversely affect the operation of existing feeders.

When overhead PTA-P welds were made using a carrier gas flow rate of $2 \mathrm{~L} / \mathrm{min}$ as proposed by Díaz [8], perturbations in powder flow were observed. This phenomenon was photographed and is shown in Figure $2 \mathrm{~d}$. Clusters of particles (like those circled in the photograph) appear and disappear randomly in the part of the pneumatic conveying line where the material starts to rise, causing perturbations in the powder flow. These variations produce deposits with irregular surfaces, as shown in Figure $2 \mathrm{e}$, which adversely affect the final coating. When the carrier gas flow rate is increased to $5 \mathrm{~L} / \mathrm{min}$ (in an attempt to avoid the phenomenon described above) there is inadequate melting at the sides of the tracks, as reported by Diaz [8], leading to defects like those identified in liquid penetrant tests in the coating shown in Figure $2 \mathrm{f}$.
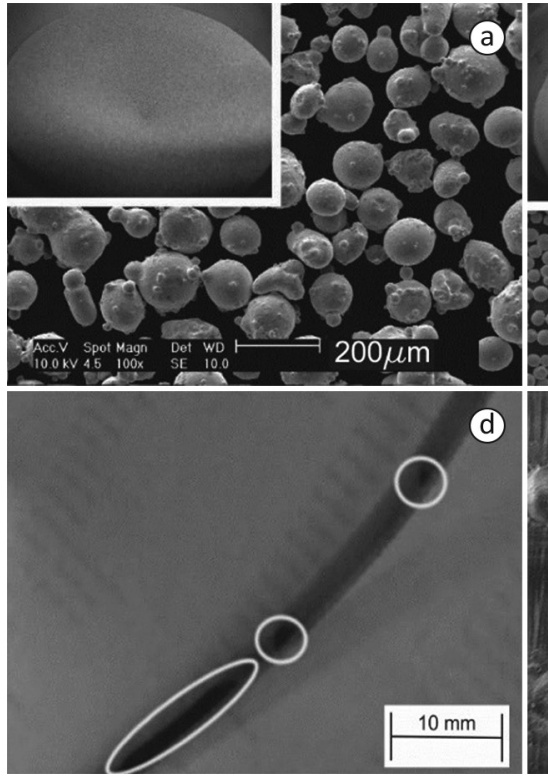
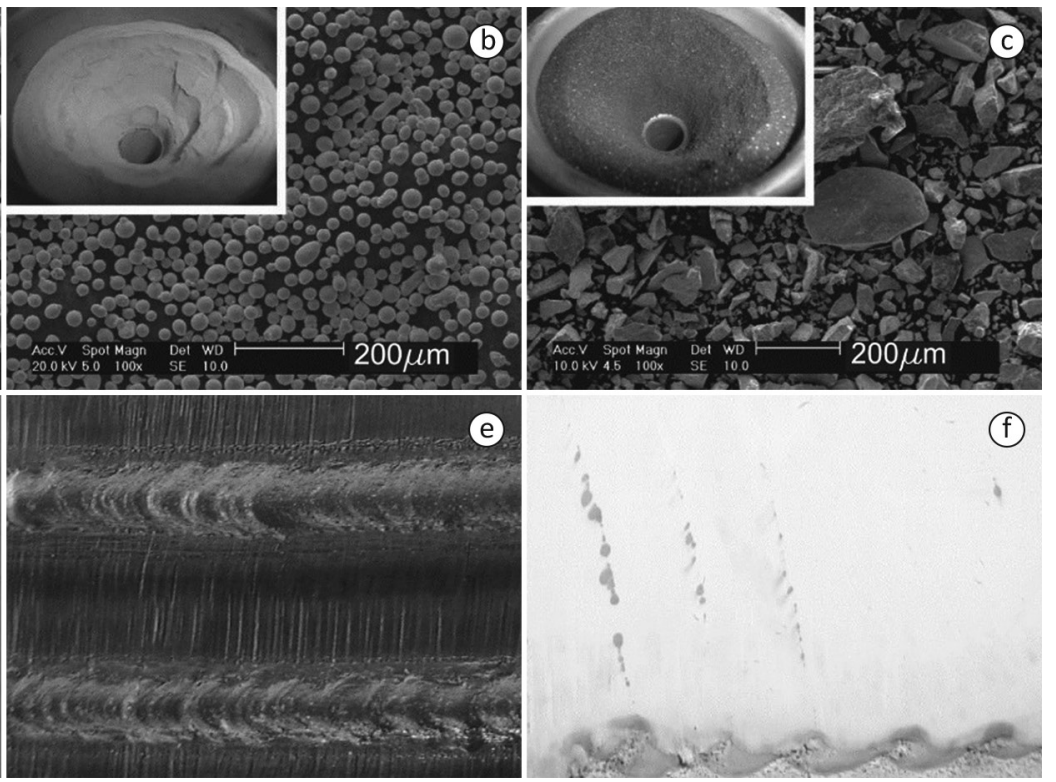

Figure 2. Feed difficulties with non-standard powders and overhead welds.

\section{Design of the New Powder Feeder}

As shown in Figure 3, the powder feeder consists of a hopper to store the powder, a rotary valve (to dose the consumable) and a component called a fluidizer, whose function is to ensure that there is a continuous stream of particles at low carrier-gas flow rates. The main features of the design and operation of the three components are discussed below.

\subsection{Hopper}

Three important characteristics were taken into consideration in the design of the hopper: the angle of the funnel at the base, the diameter of the outlet and the inside rims on the base and top. An angle of $60^{\circ}$ was suggested by Ribeiro [6] to be adequate to ensure that non-standard materials flow in the hopper and was adopted here. According to Schulze [9], when the angle of the wall of the base is not suitable for the material being used a flow defect known as rat-holing can occur. When this happens only the material directly in line with the outlet flows out of the hopper, as shown in Figure 4a. 
Development of a Powder-Feed Device and Procedures for the Application of an Experimental Alloy in Overhead PTA-P Welding

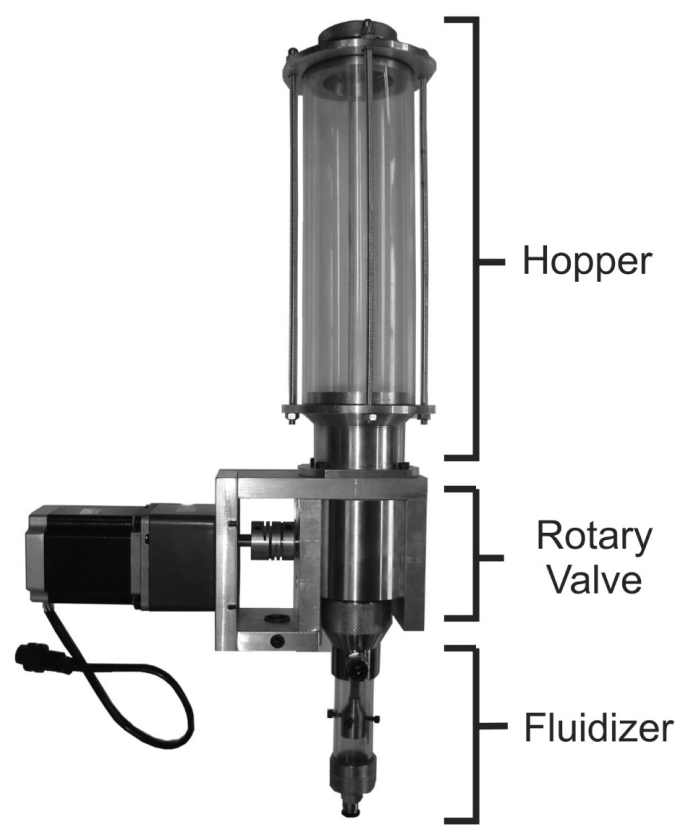

Figure 3. Prototype of the RV-F PF.
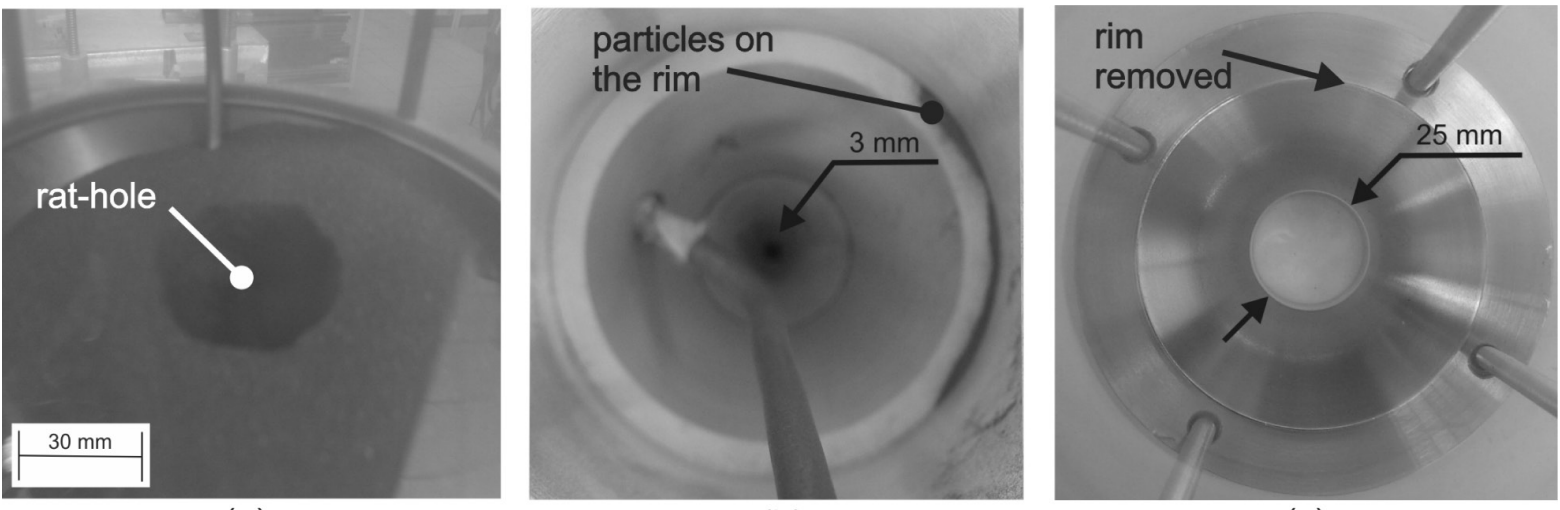

Figure 4. Factors taken into account in the design of the hopper: (a) flow interrupted by a rat-hole; (b) base of a commercial PF seen from above; (c) base of the RV-F PF hopper seen from above.

According to Marinelli and Carson [10], the cross section of the outlet should be as close as possible to that of the hopper itself. If the outlet is too small, it can prevent the powder flowing and cause blockages. An outlet diameter of $25 \mathrm{~mm}$ was therefore used in the present design. This is considerably larger than the values used in traditional feeders, as shown in Figures $4 \mathrm{~b}$ and $\mathrm{c}$. These pictures also show that the internal rim on the base of the hopper was eliminated to prevent particles getting stuck, as shown in Figure 4b. This is important to avoid other consumables being contaminated. The rim on the top of the hopper was also eliminated for the same reason.

\subsection{Rotary valve}

In the RV-F PF a rotary valve was used instead of the dosing mechanisms found in traditional feeders. In the case of a horizontal screw conveyor, the literature suggests this produces a discontinuous powder flow [11], while with a treadmill conveyor, the diameter of the outlet $(25 \mathrm{~mm})$ would require the equipment to be too big to be portable. 
The rotary valve, which is shown in Figure 5, consists basically of a rotor (with cavities where the powder is collected) that turns inside a housing. Dosing takes place when the cavities are aligned with the hopper outlet and fill with metal powder, as shown in Figure 5a. In the valve designed here, even materials that do not flow easily, such as ground and finely atomized powders, can be handled as the powder inlets and outlets in the valve have the same diameter as the outlet at the base of the hopper $(25 \mathrm{~mm})$. As the consumable must be fed continuously in PTA-P, the rotor was designed with two rows of cavities that are out of phase with each other. In this way, when one row is finishing dispensing powder the other is already starting. The inside of the housing is covered with a polymer lining as shown in Figure 5b. The purpose of this is to reduce the wear on the valve caused by friction between the powder and moving parts. Without the lining, the particles at the top of each cavity are exposed to shear stress along the dotted line in Figure $5 \mathrm{c}$. This shear stress is a result of the movement of the rotor in relation to the housing (both of which are made of 309 stainless steel) and the consequent opposing forces on the particles. These forces are represented by the arrows in Figure $5 \mathrm{c}$. The polymer lining is able to deform elastically and allow these particles to move, as shown in Figure $5 \mathrm{~d}$. Any wear is therefore reduced.
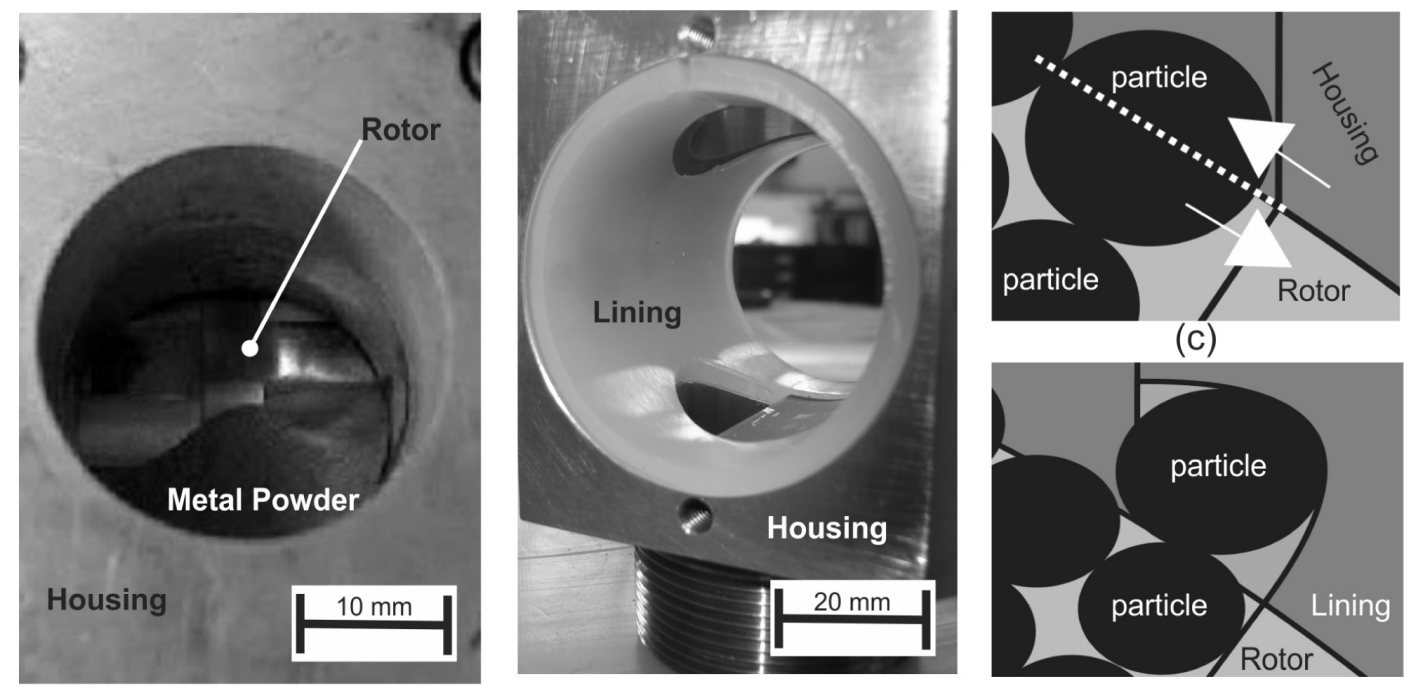

Figure 5. Rotary Valve: (a) rotor collecting metal powder; (b) lining inside the housing; (c) shear forces on particles during dosing; (d) elastic deformation of the lining.

\subsection{Fluidizer}

The metal particles are dispensed by the rotary valve and fall into the fluidizer. This is shown in Figure 6a. The particles then accumulate in the fluidizer to form a bed, as shown in Figure 6b, and the center of the bed is expanded by a gas jet flowing through a retractable opening in the middle of the fluidizer base. The particles in the path of the gas are swept upward toward the powder collector at high speed, as shown in Figure 6c. The powder collector then routes them to the pneumatic conveying line.
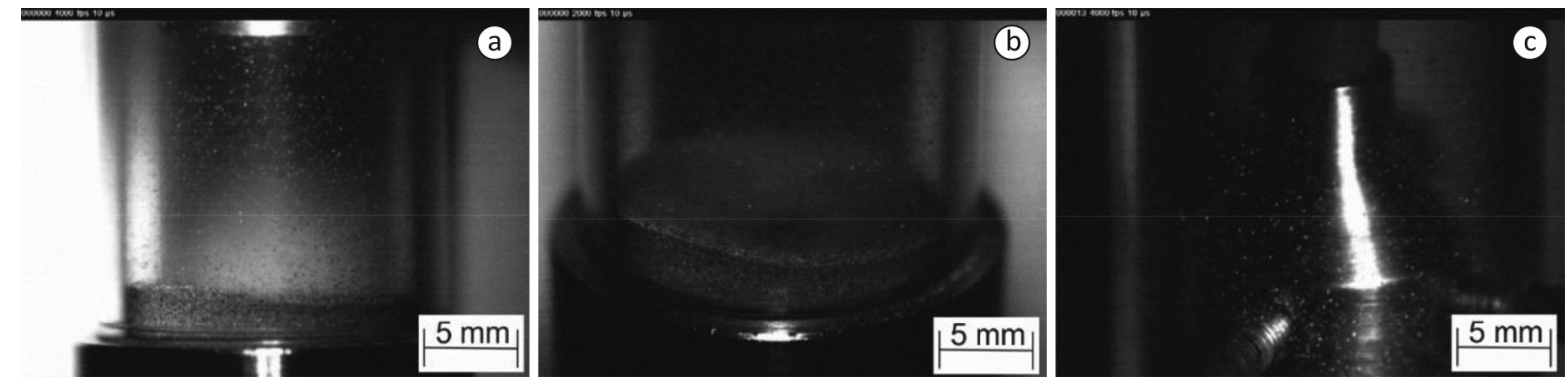

Figure 6. Fluidizer: (a) particles in suspension above the bed; (b) particles being deposited on the base to form the bed; (c) particles in the region of the powder collector. 
Development of a Powder-Feed Device and Procedures for the Application of an Experimental Alloy in Overhead PTA-P Welding

Any perturbations caused by dosing should be reduced by the powder in the fluidized bed. When the feed to the fluidizer is momentarily interrupted, the gas jet continues to sweep the particles in the fluid bed upward, preventing any changes in the amount of consumable in the pneumatic conveying line. The emulsification of the powder with the carrier gas inside the fluidizer in turn allows the consumable to be injected into a hose with a smaller diameter. With normal flow rates, a smaller-diameter hose can provide the particles with enough energy to overcome gravity [12]. Therefore, an internal diameter of $2.0 \mathrm{~mm}$ was chosen for the conveying line from the fluidizer rather than the diameter of $3.5 \mathrm{~mm}$ normally used.

\section{Materials and Methods Used to Evaluate the Rv-F Pf}

The ability of the system to feed non-standard powders was assessed by visually monitoring the powder jet at the outlet of the pneumatic conveying hose and observing whether the flow was continuous. This was done for each of the materials listed in Table 1. Which, shown in Figure 7, were used in the as-supplied state without any changes to their particle size or shape.

Table 1. Materials used to evaluate the RV-F PF.

\begin{tabular}{lccc}
\hline \multicolumn{1}{c}{ Material } & Classification & Shape & Particle size \\
PTA-P 200 & Traditional & Spherical & $+53-200 \mu \mathrm{m}$ \\
INCONEL 625 & Traditional & Spherical & $+53-150 \mu \mathrm{m}$ \\
316 L STAINLESS STEEL & Alternative & Spherical & $+11-45 \mu \mathrm{m}$ \\
Fe-Ni & Alternative & Irregular & $+15-500 \mu \mathrm{m}$ \\
BRONZE & Alternative & Irregular & $+40-200 \mu \mathrm{m}$ \\
MANGANESE & Alternative & Irregular & $+5-150 \mu \mathrm{m}$ \\
\hline
\end{tabular}
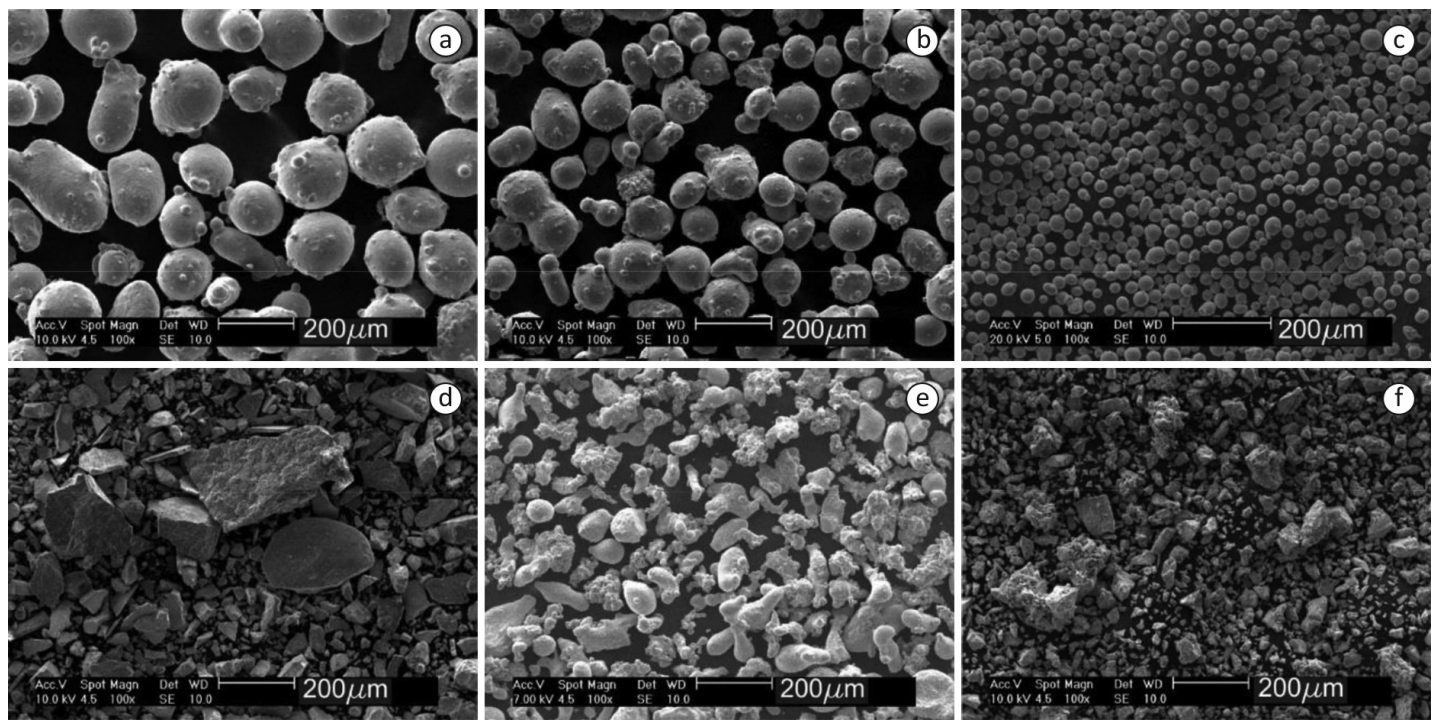

Figure 7. Metal powders used in the tests to evaluate the RV-F PF: (a) PTA-P 200; (b) INCONEL 625; (c) 316L STAINLESS STEEL; (d) Fe-Ni; (e) BRONZE; (f) MANGANESE.

The performance of the device when used to feed powder in out-of-position welding was investigated in a practical welding experiment in which part of a test specimen was coated in an overhead position. The conditions in which the RV-F PF was tested can be seen in Figure 8, which shows the welding bench and the test specimen in position. The arrow in Figure 8a points to the PF, which was positioned on a stand below the level of the welding torch. This position was chosen to increase the effect of gravity on the pneumatic conveying line and so test the device under more extreme conditions. The same figure shows the welding table at an angle of $135^{\circ}$ to the horizontal with the test specimen attached to it in the overhead position. 


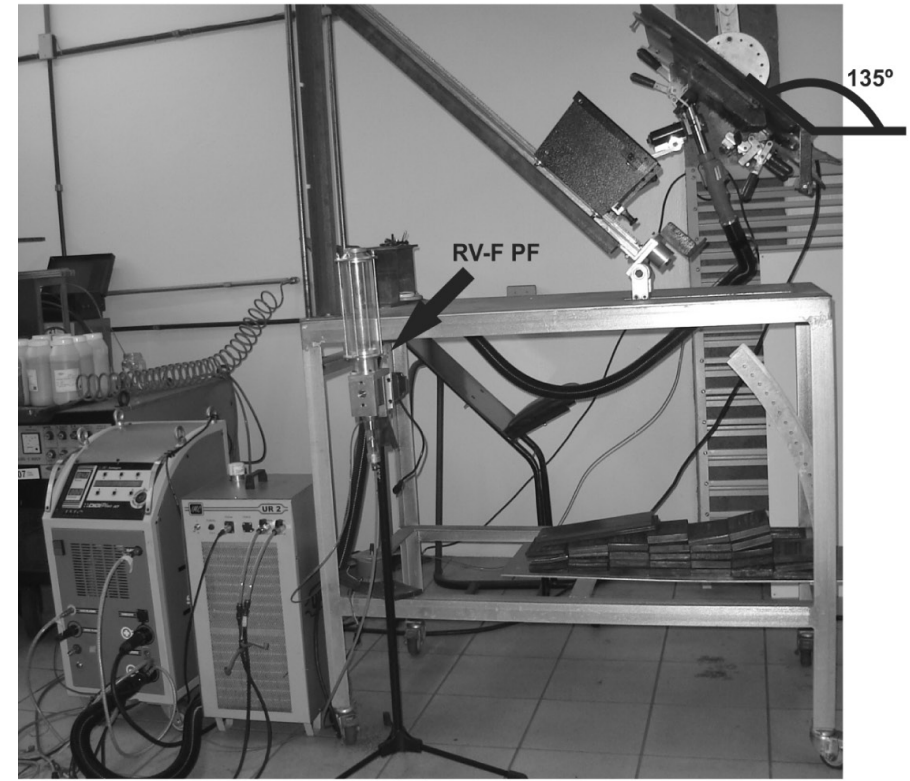

(a)

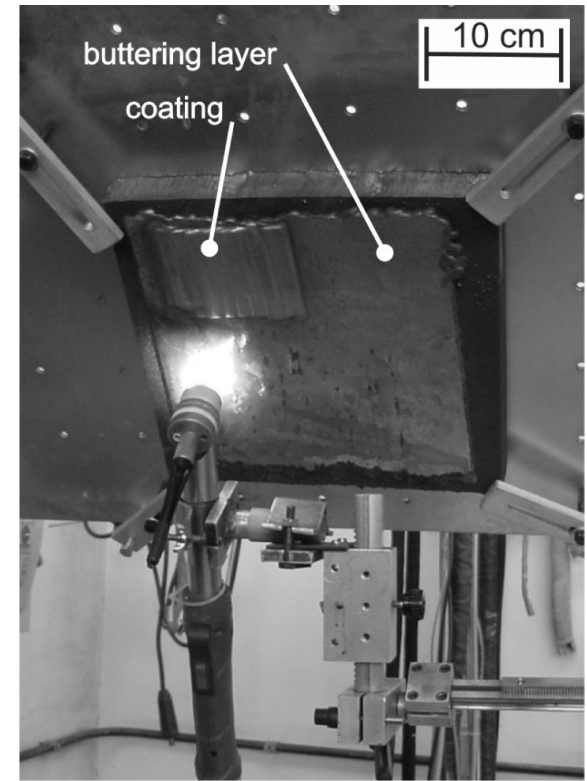

(b)

Figure 8. PTA-P bench: (a) position of the RV-F PF and welding table; (b) arrangement for securing the test specimen.

The test specimen used was made of ABNT 1020 steel, was 1 inch thick and measured $30 \times 30 \mathrm{~cm}$. These dimensions were chosen to ensure that any heat generated was dissipated quickly and so simulate as closely as possible the conditions when turbine blades are welded. Another technique used when welding turbine blades that was adopted here was to cover the area to be coated with an intermediate layer of 309 stainless steel. This layer, which is known as a buttering layer, acts as an interface to promote deposition and ensure the alloy coating has the desired metallurgical properties after welding.

The consumable was a mixture of metal powders used to produce an experimental alloy known as STENOX that was then subjected to cavitation testing. The mixture consisted of two commercial alloys: STELLITE 6, which is based on cobalt, has high cavitation resistance and is expensive, and $316 \mathrm{~L}$ stainless steel, which has low cavitation resistance and is less expensive than STELLITE 6. As cobalt is essential for conferring high cavitation resistance [13-15] but also accounts for the high cost of alloys, another commercial alloy (referred to as C ALLOY here), which contains only $9.0 \%$ cobalt and has high cavitation resistance, was used as a reference. A STENOX mixture of $13 \%$ by weight STELLITE 6 and $87 \%$ by weight 316L stainless steel was therefore chosen to give a nominal $9.0 \%$ cobalt content. The composition of the materials used is shown in Table 2. The Stellite 6 and 316L stainless steel have particle sizes in the range 53 to $150 \mu \mathrm{m}$ (i.e., the values normally used for PTA-P). Although a carrier gas flow rate of around $2.0 \mathrm{~L} / \mathrm{min}$ should be used to avoid any defects, it was decided to use a value of $2.5 \mathrm{~L} / \mathrm{min}$ as this produces a stronger powder jet.

Table 2. Chemical composition (\% by weight) of the materials used in the overhead PTA-P welding test.

\begin{tabular}{lcccccrcc}
\hline \multicolumn{1}{c}{ Element } & Fe & Co & Cr & Ni & Mo & Mn & Si & C \\
1020 STEEL & 99.15 & 0.0 & 0.0 & 0.0 & 0.0 & 0.5 & 0.05 & 0.2 \\
309 STAINLESS STEEL & 60.2 & 0.0 & 23.0 & 13.5 & 0.0 & 2.0 & 1.0 & 0.2 \\
316L STAINLESS STEEL & 68.5 & 0.0 & 16.2 & 11.2 & 2.5 & 0.9 & 0.7 & 0.05 \\
STELLITE 6 & 0.0 & 70.1 & 28.0 & 0.0 & 0.0 & 0.5 & 0.3 & 1.1 \\
C ALLOY & 60.6 & 9.0 & 17.0 & 0.0 & 0.0 & 10.0 & 3.0 & 0.2 \\
STENOX & 59.6 & 9.0 & 17.7 & 9.7 & 2.2 & 0.9 & 0.7 & 0.2 \\
\hline
\end{tabular}


Development of a Powder-Feed Device and Procedures for the Application of an Experimental Alloy in Overhead PTA-P Welding

\section{Results and Discussion}

The RV-F PF was able to handle the materials being tested efficiently. In all the cases tested, the particle jet was constant, did not change direction and was free from perturbations while the $1000 \mathrm{~g}$ in the hopper were being discharged.

Figure 9 shows pictures from the films of the experiments with each powder. There were no signs of flow defects inside the hopper. However, some differences were observed between traditional and non-standard powders in the way the powder jets behaved at the hose outlet. With traditional powders, the jet remained more concentrated than the jet formed with non-standard materials, which tended to be distributed across the whole cross section of the hose. In the latter case, small fragments (of which there are more in non-standard powders) may, because they are lighter, be transported even in regions where the gas moves more slowly (e.g., near the wall of the hose).
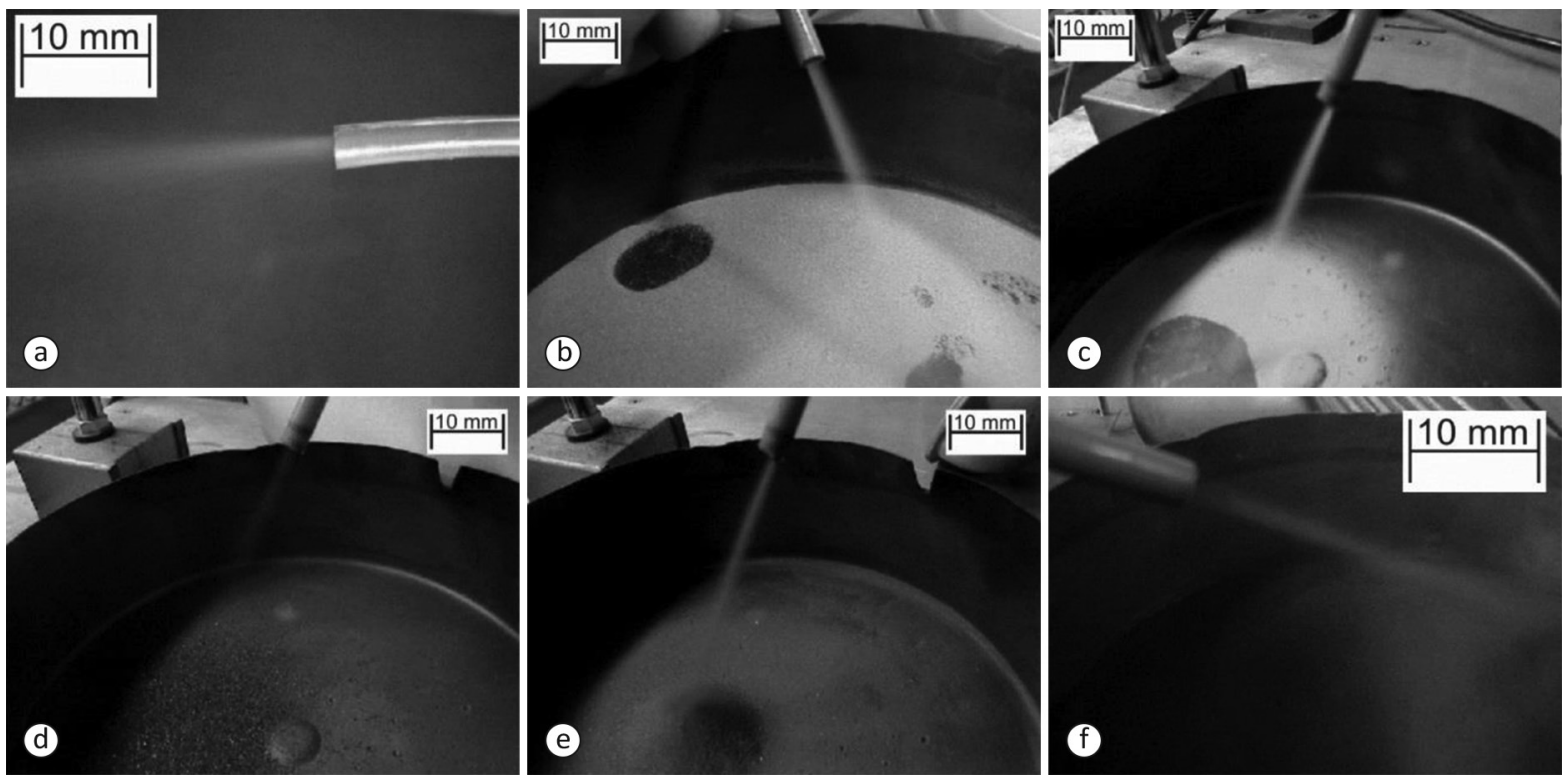

Figure 9. Powder jet at the outlet of the pneumatic conveying line: (a) PTA-P 200; (b) INCONEL 625; (c) 316L STAINLESS STEEL; (d) Fe-Ni; (e) BRONZE; (f) MANGANESE.

The results of overhead welding are shown in Figure 10. Figure 10a shows a view from above of the whole area that was coated. The appearance of the tracks reflects the satisfactory performance of the RV-F PF when used to feed powder against gravity. Visual examination shows the similarities between the tracks forming the coating, indicating that when used with the device, out-of-position PTA-P welding is reproducible and stable. The only exception was the last track (on the right), which had a crater at the beginning (produced by spray transfer) and irregularities along its right edge. These defects are a result of the high temperature of the specimen during the final stages of the welding. The detail of region 1 provides a rough view of the tracks and clearly shows the regular surface and the absence of any unmelted powder.

The macrograph in Figure $10 \mathrm{~b}$ corresponds to a cross section of the area shown in detail 2 and shows there is very little penetration of the first layer into the substrate, which was diluted by about $5 \%$. This level of dilution was considered satisfactory, and a test specimen was therefore produced to test the cavitation resistance of the STENOX alloy. Figure 11a shows this test specimen after it was exposed to liquid penetrants. There are no cracks or pores on the surface, demonstrating the importance of using a low carrier-gas flow rate (around $2.5 \mathrm{~L} / \mathrm{min}$ ). A higher flow rate $(4.0 \mathrm{~L} / \mathrm{min})$ resulted in inadequate melting between tracks, as shown in a test specimen taken from a STENOX coating in Figure 11b 

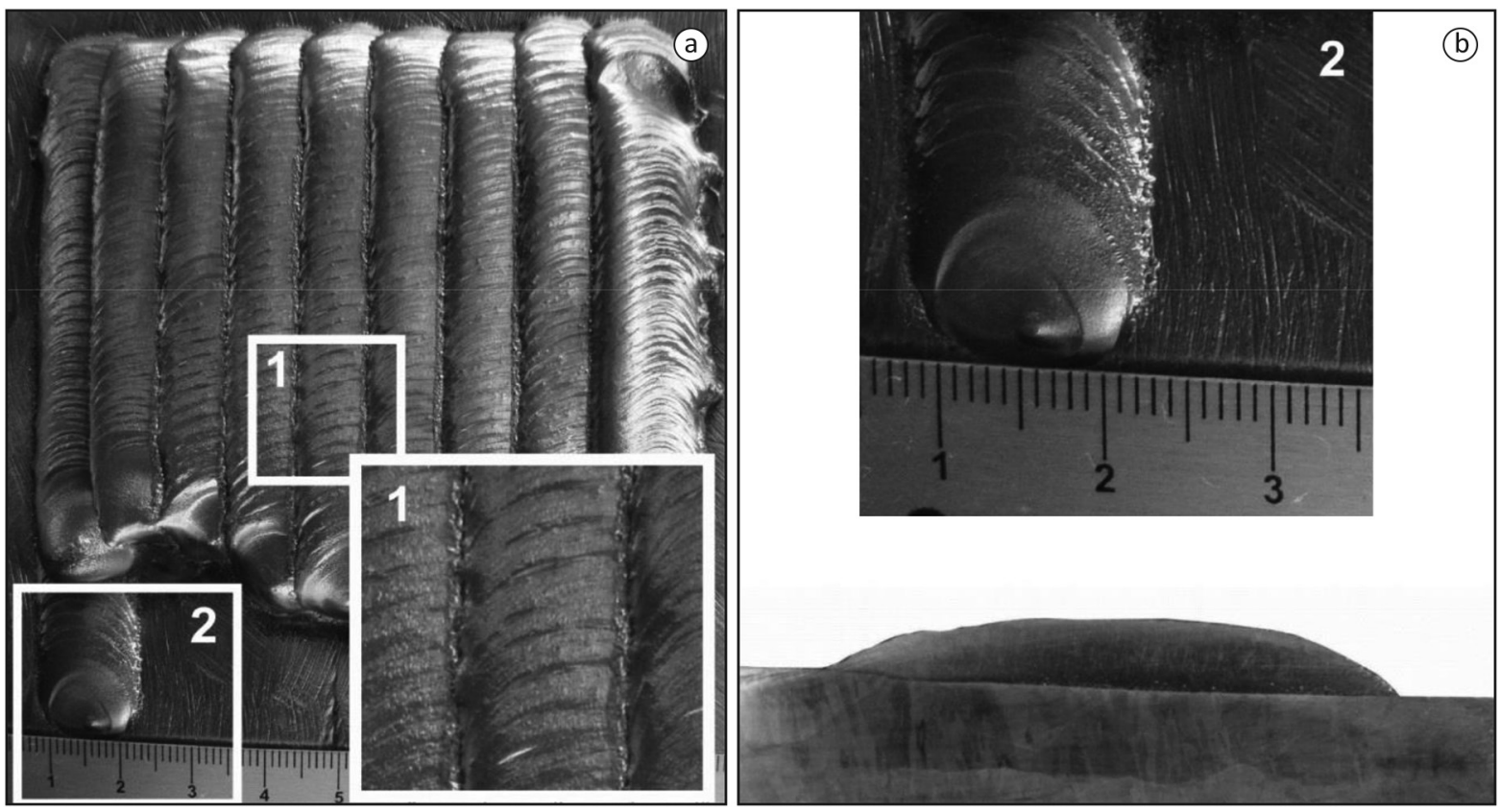

Figure 10. STENOX coating: (a) view of the coating from above with details of the surface; (b) area where the cross section was taken and macrograph of the cross section.
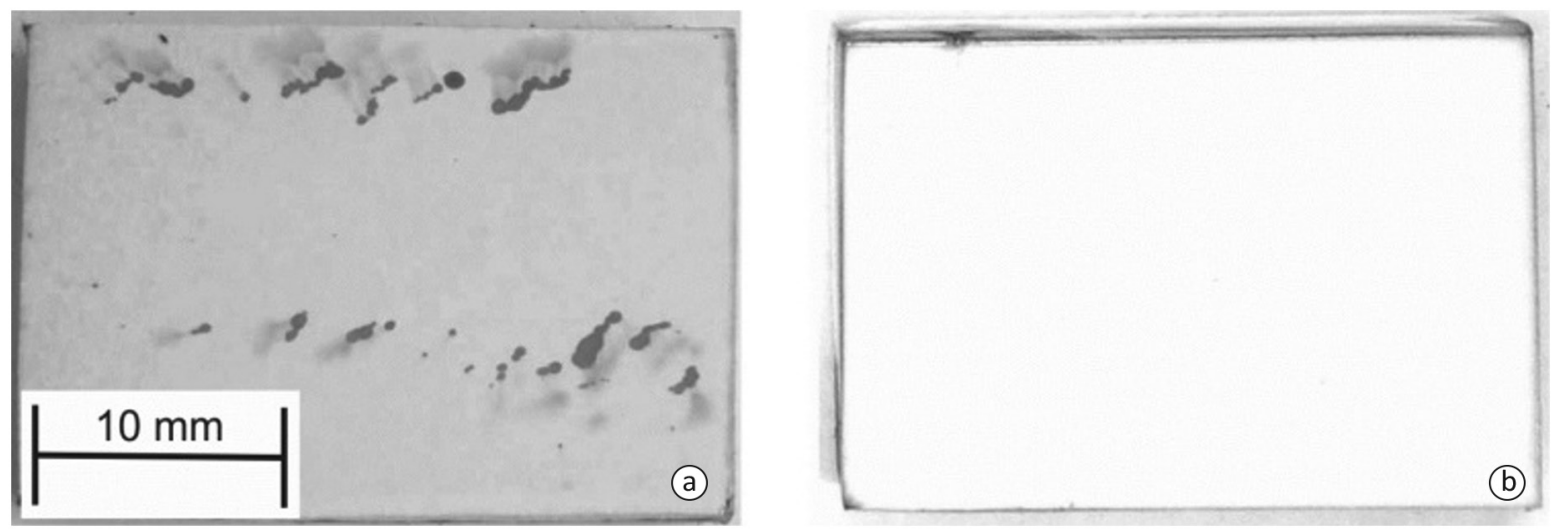

Figure 11. Test specimens used in the cavitation tests: (a) STENOX with a carrier-gas flow rate of $4.0 \mathrm{~L} / \mathrm{min}$; (b) STENOX with a carrier-gas flow rate of $2.5 \mathrm{~L} / \mathrm{min}$.

The low dilution and absence of any cracks or pores indicate that the cavitation resistance observed for STENOX corresponds to its resistance without the influence of any defects and with little interference from the metallurgical properties of the substrate. Nonetheless, the graph in Figure 12, where the performance of STENOX can be compared with the results for its constituent alloys, shows that STENOX is only slightly more resistant to cavitation than $316 \mathrm{~L}$ stainless steel. This small increase in resistance may be a consequence of the $9.0 \%$ cobalt in the alloy. However, the cavitation resistance of STENOX is far inferior to that of the commercial alloys shown in the same graph. 
Development of a Powder-Feed Device and Procedures for the Application of an Experimental Alloy in Overhead PTA-P Welding

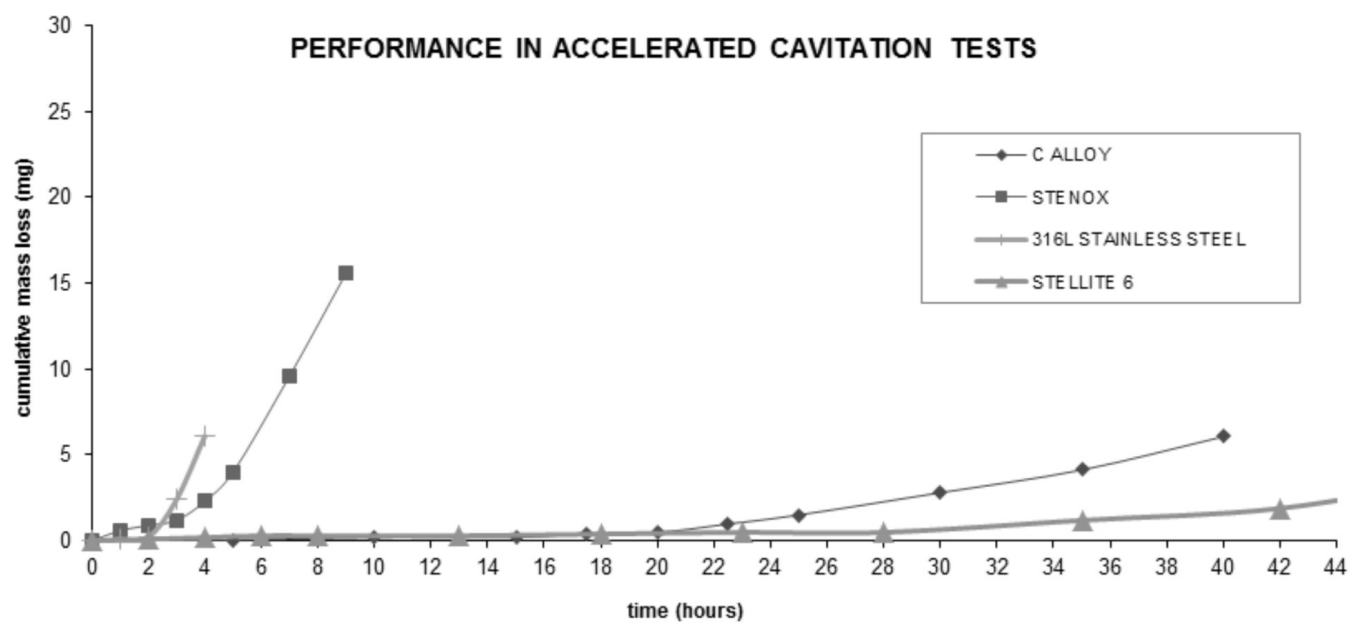

Figure 12. Performance of STENOX and its constituent alloys in cavitation tests.

\section{Conclusions}

In view of its satisfactory performance when used with non-standard consumables in overhead welding, the RV-F PF can be considered a promising technological option that will allow PTA-P welding to be used in a wider range of applications, supporting both scientific development and the needs of Brazilian industry.

Studies to develop special metal alloys will benefit from the powder feeder described here as it can be used with non-standard consumables. By making PTA-P more flexible in terms of consumable characteristics (particle shape and size), the range of materials that can be used by metallurgists can be greatly extended. This is fundamental for continued research, as the characteristics of readily available commercial powders are determined by the fractionation processes used to produce them.

With the aid of this new powder feeder, PTA-P will be able to meet the needs of industry more directly since, as observed here with STENOX, a metal alloy can be developed at the same time as it is welded in the required position. This is a particularly significant advantage as the properties of a coating depend not only on the powder mixture but also on the welding process used, which in turn is entirely dependent on the welding position. Even when commercial alloys are being used, the PTA-P process, with all the potential advantages it offers, can be considered another option for out-of-position deposition, as when used with the RV-F PF it allows welding to be performed in different positions.

The RV-F PF developed here allows the PTA-P process to be considered a viable solution in many practical situations involving out-of-position welding, including when the coating must have a good surface appearance, low dilution and limited thickness. It is thus another scientific and technological resource that can be used in industrial welding in Brazil.

\section{References}

[1] Tolmasquim MT, Guerreiro A, Gorini R. Matriz energética brasileira: uma prospectiva. Novos Estudos - CEBRAP. 2007; (79):47-69. http://dx.doi.org/10.1590/S0101-33002007000300003.

[2] Dutra JC, Silva RHG. Thermal-pulsed MIG/MAG welding applied to the repair of cavitation erosion on large-scale hydraulic turbines. Welding and Cutting. 2009;8(1):27-30.

[3] Ragu, D, Webber, R. PTA proves its worth in high volume hardfacing job. Welding Journal. 1996;75(2):34-40.

[4] Arcraft Plasma Website [internet page]. [access 25 mar. 2009]. Available from: www.arcraftplasma.com
[5] Menon, R, Mosier WC. Stainless steel with improved weldability and cavitation resistance. Bowling Green: Stoody Company; 1996.

[6] Ribeiro HO. Desenvolvimento de ligas para revestimentos por PTA resistentes à cavitação [doctor thesis]. Florianópolis: Engenharia de Materiais, Universidade Federal de Santa Catarina; 2007.

[7] Plasma Master. PM-10 Powder Feeder. Operating Manual. Kiev: Plasma Master; [2009?]. 6 p.

[8] Díaz VMV. Inovação do equipamento e avaliação do Processo Plasma de Arco Transferido Alimentado Com Pó (PTAP) para soldagem fora de posição [doctor thesis]. Florianópolis: Universidade Federal de Santa Catarina; 2005. 
[9] Schulze D. Powders and bulk solids - characterization, storage and flow. New York: Springer; 2008. p. 461.

[10] Marinelli J, Carson JW. Solve solids flow problems in bins, hoopers and feeders. New York: American Institute of Chemical Engineers; 1992. p. 10.

[11] Owen PJ, Cleary PW. Screw conveyor performance: comparison of discrete element modelling with laboratorie experiments. In: Proceedings of the 7th Internacional Conference on CFD in the Minerals and Process Industries; 2009; Melbourne. Melbourne; 2009. p. 7.

[12] Mills D. Pneumatic conveying design guide. 2 nd ed. Oxford: Butterworth-Heinemann; 2004. p. 650.
[13] Will CR, Capra AR, Pukasiewicz AGM, Chandelier JG, Paredes RSC. Estudo comparativo de três ligas austeníticas com cobalto resistentes à cavitação depositadas por plasma pulsado térmico. Soldagem \& Inspeção. 2010;15(1):52-60. http://dx.doi. org/10.1590/S0104-92242010000100007.

[14] Romo SA, Santa JF, Giraldo JE, Toro A. Cavitation and high velocity slurry erosion resistance of welded stellite 6 alloy. Tribology International. 2012;47:16-24. http://dx.doi.org/10.1016/j. triboint.2011.10.003.

[15] Paul CP, Gandhi BK, Bhargava P, Dwivedi DK, Kukreja LM. Cobalt-free laser cladding on AISI type 316L stainless steel for improved cavitation and slurry erosion wear behavior. Journal of Materials Engineering and Performance. 2014;23(12):44634471. http://dx.doi.org/10.1007/s11665-014-1244-9. 